\title{
Лазерное аддитивное производство биорезорбируемых магниевых имплантатов и средства его автоматизации
}

\author{
Ю.Н. Кульчин, А.И. Никитин ${ }^{*}$, П.А. Никифоров, \\ Д.С. Пивоваров, Д.С. Яцко, В.А. Тимченко \\ Институт автоматики и проиессов управления ДВО РАН \\ *E-mail: anikitin@iacp.dvo.ru
}

DOI: 10.31868/RFL2020.154-155

Магний и его сплавы относятся к классу разлагаемых биоматериалов, имеющих механическую прочность подобную прочности кости. Оперативное создание из магниевого порошка индивидуального имплантата по электронной геометрической модели в результате лазерного аддитивного процесса исключает необходимость проведения повторной операции по его удалению. Однако сложность процесса лазерного сплавления при выполнении цикла построения детали из-за высокой химической реактивности магния, создающей риск возгорания, пока не позволяет на практике применять этот материал в медицинских приложениях: ортопедия, травматология и педиатрия. В ходе выполнения планов фундаментальных научных исследований РАН междисциплинарной группой сотрудников ДВО РАН изучено воздействие множества факторов, влияющих на механические характеристики и характеристики разложения, послойно созданных образцов из магниевого порошка МПФ-4 [1-3] в процессе аддитивного производства «прямой подвод энергии лазера и материала» (laser powder-based directed energy deposition LPDED). Проведенный анализ вариантов применения 3D-моделирования и трехмерной печати в хирургии [4] и результаты собственных исследований [5] позволили разработать алгоритм перехода от исходной информации, содержащейся в файлах компьютерной томографии, к программному коду, задающему аддитивный процесс формирования физической формы накостного имплантата путем сплавления металлического порошкового материала при воздействии энергии лазера.

Процесс поэтапного формирования концептуального прототипа накостного имплантата из порошка магния МПФ-4 схематично представлен на рисунке 1.

Для автоматизации этапа проектирования аддитивного технологического процесса синтеза имплантата по его модели предложена концепция программноинформационного комплекса поддержки принятия решений в сфере лазерного аддитивного производства LPDED на основе онтологического подхода [6].

Результаты проведенного исследования аккумулированы в информационных базах портала знаний о технологических процессах аддитивного производства металлических изделий с использованием лазерных технологических комплексов. Данный портал, в основу которого положена концепция [6], создан на облачной платформе IACPaaS $[7,8]$ и предназначен для отработки оптимальных (по критерию качества процесса аддитивного производства) технологических режимов, пригодных для практического применения.

Исследовательская работа, направленная на создание программы синтеза деталей заданной формы в процессе лазерного аддитивного производства, носила научно-практический характер, поскольку полученные результаты могут быть 
использованы в медицине, в частности, в хирургии, при изготовлении биорезорбируемых магниевых индивидуальных имплантатов для накостного остеосинтеза.

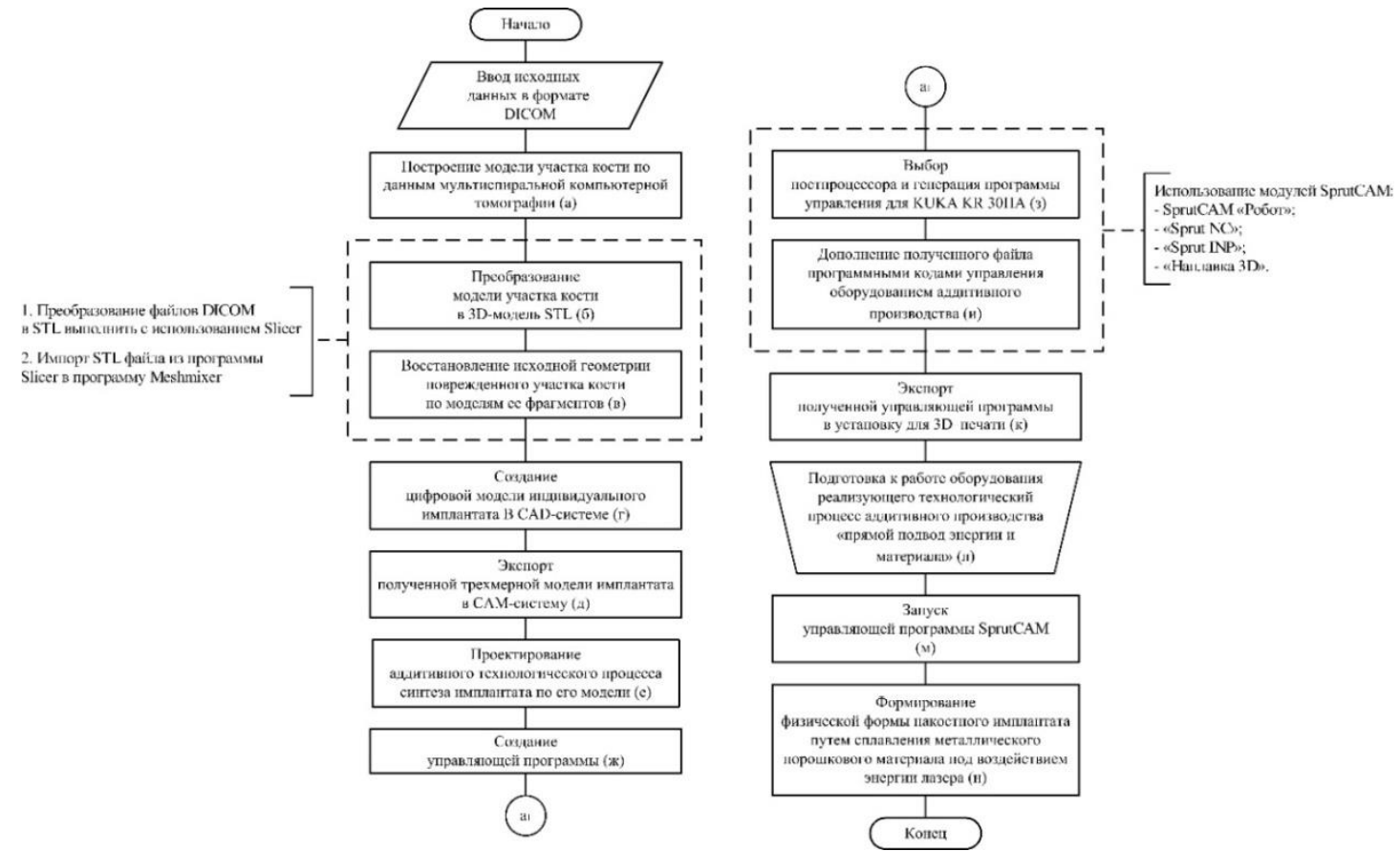

Рис. 1. Схема процесса формирования накостного имплантата по виртуальной модели для процесса аддитивного производства «прямой подвод энергии лазера и порошкового материала».

Информационные базы портала знаний будут полезны в процессе обучения операторов лазерных комплексов, а их формализованное представление обеспечит возможность использования этой информации программными системами для поддержки принятия решений.

Работа выполнена при частичной финансовой поддержке РФФИ (проект №20-0100449).

\section{Литература}

[1] Y.N. Kulchin, A.I. Nikitin et al, International Multi-Conference on Industrial Engineering and Modern technologies (FarEastCon2019) 992, 780-785 (2019).

[2] V.I. Sergienko, A.S. Gnedenkov et al, 29th International Ocean and Polar Engineering Conference, ISOPE 2019 Honolulu; USA. I-19-284 ISOPE Conference Paper (2019).

[3] S.V. Gnedenkov, S.L. Sinebryukhov et al, Journal of Alloys and Compounds 808, 151629 (2019).)

[4] А.Н. Николаенко, Применение 3D-моделирования и трехмерной печати в хирургии (обзор литературы), Medline.ru 19(2), 20-44 (2018).

[5] Sinebryukhov S.L., Gnedenkov S.V., Kulchin Y.N. et al, Asia-Pacific Conference on Fundamental Problems of Opto- and Microelectronics 2017 11024, (2017).

[6] В.В. Грибова, В.А. Тимченко, Онтология проектирования 10(2), 176-189 (2020)

[7] В.В. Грибова, А.С. Клещев и др., Программные продукты и системы 31(3), 527-536 (2018).

[8] Gribova Valeria, Kleschev Alexander et al, Открытые семантические технологии проектирования интеллектуальных систем 3, 21-24 (2019). 